\title{
Interview with Singapore Filmmaker Boo Junfeng
}

\author{
By Yvonne Ng
}

Fall 2010 Issue of KINEMA

BOO JUNFENG is a young Singapore filmmaker (b. 1983) who came into the media spotlight after his first feature, Sandcastle (2010), was invited to premiere in the International Critics' Week (Semaine de la critique) at the Cannes IFF and to compete for the Caméra d'Or award. At this point, the director already had behind him seven successful shorts and an episode in the feature Lucky 7 (2007).

A top student at the School of Film and Media Studies at Ngee Ann Polytechnic, Singapore, he was awarded the Shaw Foundation Gold Medal and the Media Development Authority Prize as the top graduate of his class. His short film debut, Un retrato de familia (A Family Portrait, 2004), produced during his stay on an exchange programme at the Escola Superior de Cinema i Audiovisuals de Catalunya won the Silver Screen Awards for Best Film and Special Achievement at the $18^{\text {th }}$ Singapore IFF. In 2005, Junfeng was selected as one of twenty participants from Asia for the inaugural session of the Asian Film Academy in Korea, headed by the well-known Taiwanese director, Hou Hsiao Hsien.

Thematically, Junfeng's films revolve around personal and family relationships (Family Portrait, Katong Fugue, Bedok Jetty, Keluar Baris, Tanjong Rhu, Sandcastle); they also touch on issues of culture, history, politics and homosexuality (for example Katong Fugue, Tanjong Rhu and Threshold). The latter subject, although no longer an absolute taboo in Singapore, nevertheless caused the withdrawal of Tanjong Rhu and Threshold from screening at the National Museum Cinémathèque in 2009 (even though both films had been granted R21 status by the Board of Film Censors).

Kinema: When and how did your interest in filmmaking begin?

Boo Junfeng: I was first interested in filmmaking when I was fifteen. At that time, I was exposed mainly to Hollywood films and was very interested in seeing behind-the-scenes documentaries about the making of movies. The idea of make-belief in filmmaking was both intriguing and inspiring. When I found out that there was a film school in Singapore at Ngee Ann Polytechnic, I decided that was what I wanted to go into. I was sixteen when I first went to film school.

You were on an exchange programme in Barcelona, Spain. How long were you there for and how did this experience affect you?

I was there for six months when I was nineteen. Two of us from Ngee Ann Polytechnic went that year. We couldn't understand what was going on in class because the lessons were taught in Catalan. So we had an agreement with the school that as long as we made a film there, we would pass the course. When I was at Ngee Ann, I specialised mainly in art direction, so this was the first time I had the opportunity to write and direct my own short film. I pretty much threw myself in the deep end for that project - doing it for the first time, with a cast and crew that spoke mainly Spanish, and in an entirely different culture. It was a great learning experience.

In several of your shorts, you explore actual events that are in danger of being forgotten, and your first feature Sandcastle involves the Chinese school students riots in 1956, a period that is little known by the young or has somehow been suppressed by the collective memory. Could you tell us more about what you hope to achieve by focusing on these events?

There's something about stories that are anchored in the past that is very alluring for me. I find it hard to explain.

Sandcastle is your first feature film which you both wrote and directed. Could you tell us more about why you wanted to make this film?

The inspiration for the original story came from living with my grandmother over the last few years of her life. I witnessed her memory deteriorating with dementia, how it turned her into a different person during her moments of delirium, and how it affected the dynamics of my family. The original story was aimed at addressing that pain, and the moral dilemmas associated with caring for an aged family member in Singapore. However, my grandmother passed away shortly after I had finished the first draft. While 
dealing with her demise, it felt impossible to continue with the original thread. I decided then to shift the focus thematically away from the illness and the pain it caused, to the idea of memory and how transient and mutable it is.I wanted to expand the idea of memory beyond the personal, and decided to weave in a back-story for the family in the film that was inspired by the political uprising of students in Chinese schools in Singapore, in the 50s and 60s. The students were patriotic, anti-colonial and left-leaning. Students as young as 14 had ideological convictions that led them to boycott exams, organise rallies and stage protests. That kind of fervour is unthinkable for a Singaporean like me who was born in the 1980s. It amazes me how different circumstances have become over just one generation. I believe it is a period in history Singaporeans should feel free to talk about.

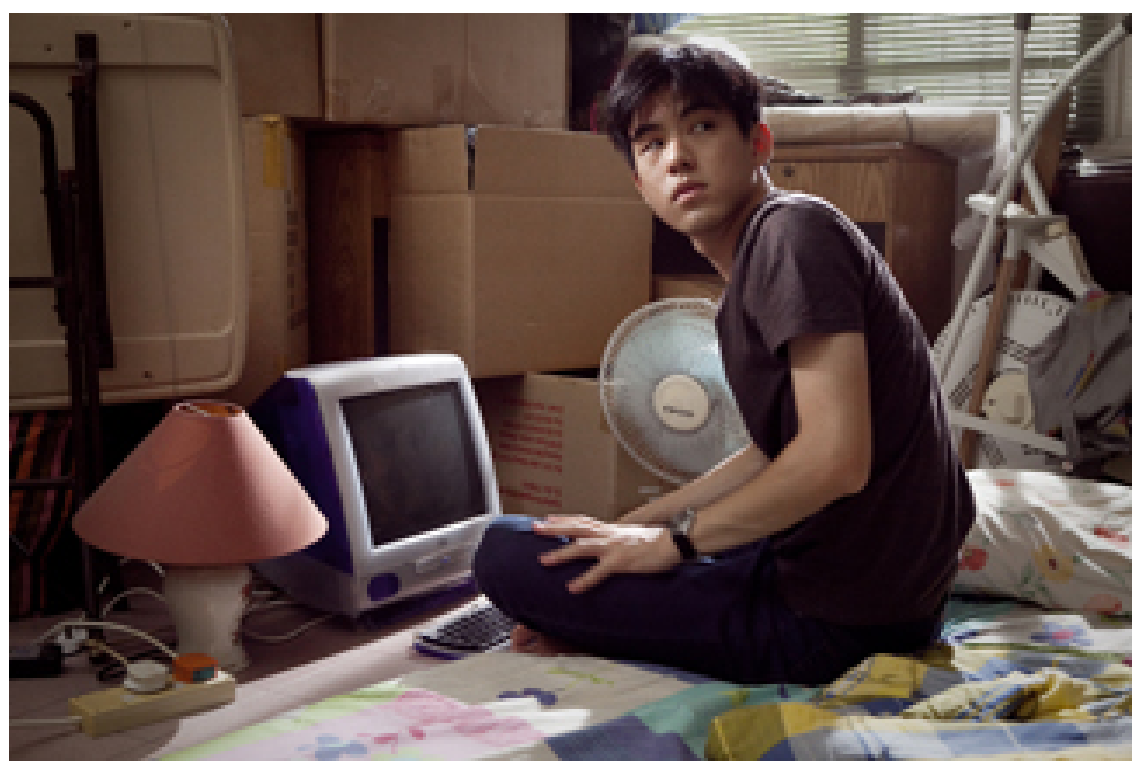

Figure 1: Joshua Tan in Sandcastle

What was the film's budget and how was it funded?

The film was made for about USD 250,000. It was primarily funded by the Singapore Film Commission under their New Feature Film Fund scheme. The other partners are Zhao Wei Films, Fortissimo Films and Peanut Pictures, which is my own company.

Most of your films - Family Portrait, Katong Fugue, Bedok Jetty, Keluar Baris, Tanjong $\mathrm{Rhu}$, Sandcastle - revolve around personal or family relationships. Is this a theme of particular interest or importance to you?

Yes. I've come to believe that good narrative filmmaking is a craft that requires a lot of life experience. As a young filmmaker, I can only tap into themes and relationships that I understand, and family is one of them. I enjoy working out the different dynamics and relationships within a family unit, and the various configurations that a family can come in.

Your films have been mostly appreciated by non-mainstream audiences. How do you see the filmmakers' old dilemma between personal integrity and commercial pressures?

I believe a good narrative filmmaker does need to keep his or her audience in mind when making films. I don't see it as a dilemma necessarily, but possibly a dialogue.

\section{What was the most difficult hurdle when shooting Sandcastle?}

In developing the script. After making a number of short films, I thought I knew how to make a movie. But making a full-length film is quite a different ball game altogether. I was pretty much feeling my way around in the dark and had to figure out many things on my own.

What were you most concerned with in the making of Sandcastle?

That the film was going to outlive me and I didn't want to screw it up. 
If you had a choice, would you prefer to be a short or feature filmmmaker and why?

Feature filmmaking. I've fallen in love with the process of making full-length films.

How do short and feature films compare to you from the point of creative freedom?

For shorts, I'm allowed to experiment more and make choices that can be entirely self-indulgent. I can't do that as much for a feature film because of the amount of resources put into it. I have to assess what is accessible to the audience and what isn't, and I like the challenge of finding that balance.

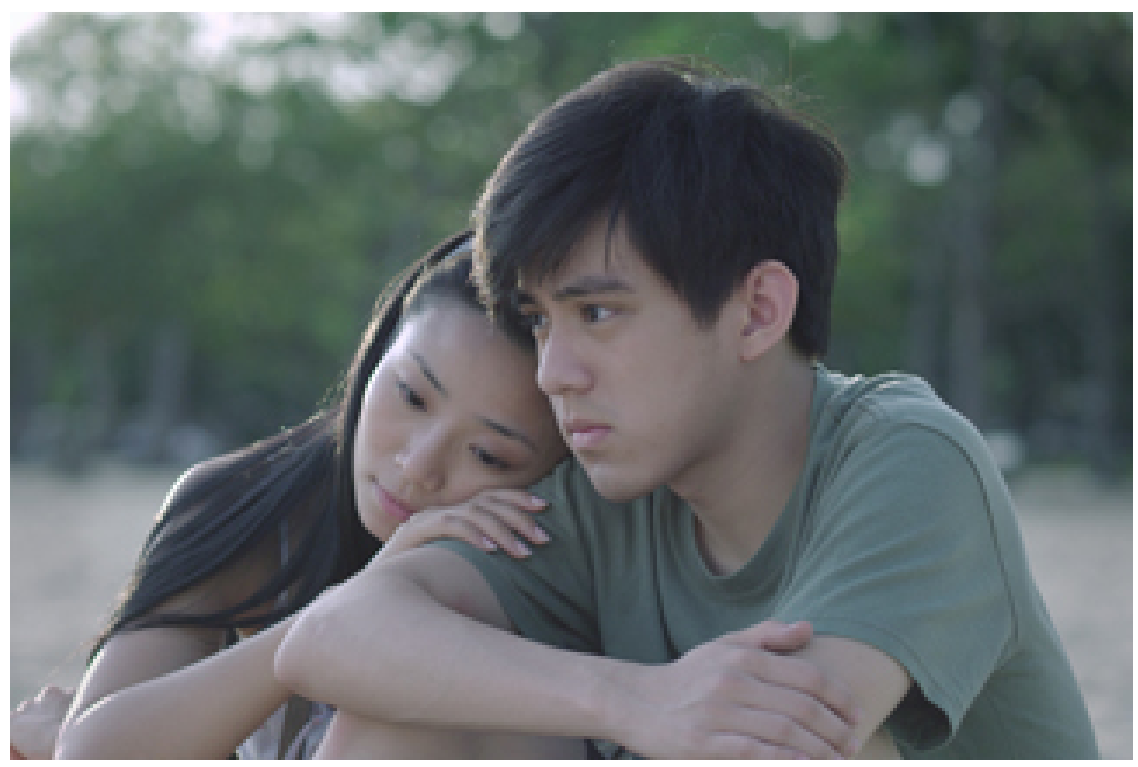

Figure 2: Bobbi Che, Joshua Tan in Sandcastle

You've travelled to number of international film festivals, especially with Tanjong Rhu, shown in Berlin in 2009 and with Sandcastle, which participated at Cannes in 2010. Was there anything that struck you about the audience response overseas compared to home audiences?

Because some of the themes touched on in Tanjong Rhu and Sandcastle are very specific to Singapore, the audience in Singapore react a lot stronger to them. Travelling with the films have allowed me to identify the themes that are more universal. For Sandcastle, people overseas tend to react more to the coming-of-age and dementia themes.

Have you been thinking about your next movie, and if yes, could you tell us something about your ideas and plans?

I'm thinking of a few ideas but nothing worth mentioning yet.

What does filmmaking mean to you?

Storytelling.

\section{References}

\section{Boo Junfeng Filmography}

\section{Shorts}

Guo ke (Stranger, 2004)

Un retrato de familia (A Family Portrait, 2004)

The Changi Murals (2006)

Katong Fugue (2007)

Bedok Jetty (2008)

Keluar Baris (2008) 


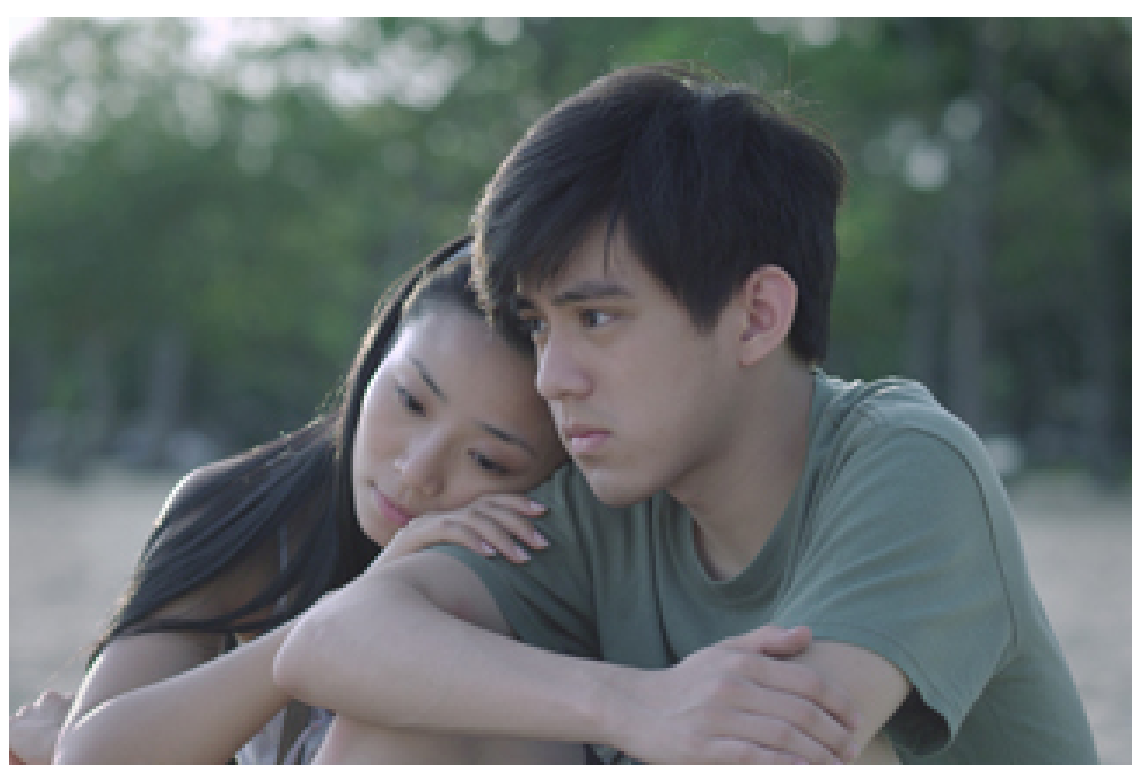

Figure 3: Sandcastle

Tanjong Rhu (2008)

Threshold (2009)

\section{Features}

Lucky 7 (segment, 2007)

Sandcastle (2010)

\section{Author Information}

Yvonne NG is the co-author of Latent Images: Film in Singapore Second edition (NUS Press, 2010); Latent Images: Film in Singapore (OUP, 2000) and Latent Images: Film in Singapore CD-ROM (Singapore, 2003). She has written on Singapore and Asian cinema and contributes to the International Film Guide. 